\title{
Purification of the NF2 Tumor Suppressor Protein from Human Erythrocytes
}

\author{
Hitesh K. Jindal, Kazumi Yoshinaga, Pil-Soo Seo, Mohini Lutchman, \\ Patrick A. Dion, Guy A. Rouleau, Toshihiko Hanada, Athar H. Chishti
}

\begin{abstract}
Background: Neurofibromatosis type 2 (NF2) is an autosomal dominant disease predisposing individuals to the risk of developing tumors of cranial and spinal nerves. The NF2 tumor suppressor protein, known as Merlin/Schwanomin, is a member of the protein 4.1 superfamily that function as links between the cytoskeleton and the plasma membrane. Methods: Upon selective extraction of membrane-associated proteins from erythrocyte plasma membrane (ghosts) using low ionic strength solution, the bulk of NF2 protein remains associated with the spectrin-actin depleted inside-out-vesicles. Western blot analysis showed a $\sim 70 \mathrm{kDa}$ polypeptide in the erythrocyte plasma membrane. Furthermore, quantitative removal of NF2 protein from the inside-out-vesicles was achieved using 1.0 M potassium iodide, a treatment known to remove tightly-bound peripheral membrane proteins. Results: These results suggest a novel mode of NF2 protein association with the erythrocyte membrane that is distinct from the known membrane interactions of protein 4.1 . Based on these biochemical properties, several purification strategies were devised to isolate native NF2 protein from human erythrocyte ghosts. Using purified and recombinant NF2 protein as internal standards, we quantified approximately $\sim 41-65,000$ molecules of NF2 protein per erythrocyte. Conclusion: We provide evidence for the presence of NF2 protein in the human erythrocyte membrane. The identification of NF2 protein in the human erythrocyte membrane will make it feasible to discover novel interactions of NF2 protein utilizing powerful techniques of erythrocyte biochemistry and genetics in mammalian cells.
\end{abstract}

RÉSUMÉ: Purification de la protéine codée par le gène suppresseur de tumeur NF2 à partir d'érythrocytes humains. Contexte : La neurofibromatose de type 2 (NF2) est une maladie dominante autosomique qui prédispose au développement de tumeurs au niveau des nerfs crâniens et des nerfs spinaux. La protéine codée par le gène suppresseur de tumeurs NF2, connue sous le nom de Merlin/Schwannomin, fait partie de la superfamille des protéines 4,1 impliquées dans l'interface entre le cytosquelette et la membrane plasmatique. Méthodes : Lors de l'extraction sélective des protéines associées à la membrane cellulaire d'érythrocytes plasmatiques (fantômes d'hématies) au moyen d'une solution dont la force ionique est faible, la majeure partie de la protéine NF2 demeure associée aux vésicules inversées dépourvues de spectrine-actine. L'analyse par buvardage Western a démontré la présence d'un polypeptide de $\sim 70 \mathrm{kDa}$ dans la membrane plasmatique erythrocytaire. L'élimination quantitative de la protéine NF2 des vésicules inversées a été effectuée au moyen d'iodure de potassium 1,0 M, un traitement qui extrait les protéines membranaires périphériques fortement liées. Résultats : Ces résultats sont compatibles avec un nouveau mode d'association de la protéine NF2 à la membrane érythrocytaire qui est distinct des interactions membranaires connues au sujet des protéines 4,1. Plusieurs stratégies de purification fondées sur ces propriétés biochimiques ont été élaborées pour isoler la protéine NF2 native des fantômes d'hématies humaines. Nous avons quantifié approximativement 41-65 000 molécules de protéine NF2 par érythrocyte en utilisant la protéine NF2 purifiée et la protéine NF2 recombinante comme standards internes. Conclusion : Ces données sont compatibles avec la présence de la protéine NF2 dans la membrane des érythrocytes humains. L'identification de la protéine NF2 dans la membrane des érythrocytes humains permettra de découvrir de nouveaux modes d'interactions de la protéine NF2 dans les cellules de mammifères au moyen de techniques puissantes de biochimie et de génétique érythrocytaire.

Can. J. Neurol. Sci. 2006; 33: 394-402

Neurofibromatosis type 2 (NF2) is an autosomal dominant disorder, characterized by the development of bilateral vestibular and spinal schwannomas, meningiomas, and ependymomas. ${ }^{1,2}$ The NF2 gene encodes a 595 amino acid polypeptide known as NF2 protein or Merlin or Schwanomin. The primary structure of NF2 protein is homologous to the ERM family of peripheral membrane proteins, which includes Ezrin, Radixin, and Moesin. ${ }^{3,4}$ The founding member of the ERM superfamily is the erythrocyte membrane protein 4.1 , which cross-link's spectrinactin complexes and attaches them to the plasma membrane. ${ }^{5}$
From the Departments of Medicine, Anatomy, and Cellular Biology (HKJ, ML, AHC), St. Elizabeth's Medical Center, Tufts University School of Medicine, Boston, MA, U.S.A; Center for the Study of Brain Diseases (PAD, GAR), CHUM Research CenterNotre Dame Hospital, Montreal, QC, Canada; Department of Pharmacology (KY, PSS, TH, AHC), UIC Cancer Center, University of Illinois College of Medicine, Chicago, IL, U.S.A.

ReCEIVED JANuARY 9, 2006. ACCEPTED In FinAL FORM JunE 27, 2006. Reprint requests to: Athar H. Chishti, Department of Pharmacology, UIC Cancer Center, University of Illinois College of Medicine, Chicago, IL, 60612, U.S.A. 
The ERM family members, including the distant homologues such as talin and some tyrosine phosphatases, are believed to regulate cell surface dynamics by linking the underlying cytoskeleton to membrane receptors. Several mechanisms have been proposed to explain the role of ERM proteins in signaling pathways that regulate cell growth and differentiation. ${ }^{3,6}$ More recently, extensive evidence supports a functional role of NF2 protein in the regulation of cell proliferation, motility, and adhesion pathways. ${ }^{7-12}$ Despite this progress, the precise molecular function of NF2 protein in the regulation of tumor suppression pathways remains poorly understood. For example, it is not known whether the NF2 protein exists as a monomer, dimer, or self-associates into an oligomer in order to act as a tumor suppressor protein. In addition, it remains unclear whether the NF2 protein undergoes any lipid modifications in vivo. Selfassociation and lipid modifications are common characteristics of many tumor suppressor proteins with important regulatory implications. ${ }^{13,14}$ Understanding the biochemical basis of NF2 protein interaction with the plasma membrane and identifying the respective modulators for such interactions will help elucidate the regulatory implications of the NF2 protein in tumor suppression pathways.

However, there are limitations in carrying out biochemical studies of NF2 protein. For instance, since the primary structure of NF2 protein does not encode any known enzymatic domains, most efforts have focused on the identification of binding proteins that interact either with its amino-terminal FERM domain or the carboxyl terminal regulatory domain. ${ }^{15,16}$ Nevertheless, genetic manipulations using transfected cells and lysates have demonstrated the existence of an intramolecular "close" and "open" regulatory switch in the NF2 protein. 3,17,18 Additionally, phosphorylation of the NF2 protein by several kinases and degradation of NF2 protein by calpain in vivo suggest the importance of NF2 in cellular processes. ${ }^{19-22}$ Also, the unavailability of purified NF2 protein from mammalian cells, largely due to the presence of NF2 in Schwann cells has limited the opportunity to obtain biochemically pure NF2 protein in its native form. This is perhaps one reason why the NF2 protein has never been isolated and purified from mammalian cells.

We identified NF2 protein by accident while investigating the syntenin-NF2 protein interactions by Western blot analysis of samples that included purified erythrocyte plasma membrane (ghosts) as a negative control. The identification of NF2 protein in the erythrocyte ghosts gave us an opportunity to purify human NF2 protein in its native state. Also, initial characterization studies suggested a novel association of NF2 protein with the plasma membrane. Combining established knowledge and powerful techniques of erythrocyte membrane biochemistry with the finding of NF2 tumor suppressor in the erythrocyte membrane could provide an unexpected opportunity to develop a simple diagnostic blood test for detecting truncating mutations within the Neurofibromatosis type 2 gene in order to monitor the progression of the disease in clinical settings. Some of these possibilities will be discussed.

\section{EXPERIMENTAL}

\section{Antibodies}

The anti-NF2 polyclonal antibody was raised in rabbit against the C-terminus peptide of NF2 protein isoform-1. ${ }^{23}$ This polyclonal antibody does not detect NF2 protein isoform-2. The anti-NF2 polyclonal antibody (A-19), which can detect an epitope located within the N-terminal segment of NF2 protein, was purchased from Santa Cruz Biotechnology.

\section{Blood samples}

Blood samples from protein 4.1 and glycophorin $\mathrm{C}$ deficient patients were used as described before. ${ }^{24}$ Ankyrin-deficient $\mathrm{nb} / \mathrm{nb}$ mice, spectrin-deficient $\mathrm{sph} / \mathrm{sph}$ mice, and band 4.2 null mice were obtained from the Jackson Laboratory, Bar Harbor, Maine, with the assistance of Dr. Luanne Peters. Band 3 knock out mice were generated in our laboratory as previously described. ${ }^{25}$

\section{Recombinant protein expression}

The recombinant C-terminal half (amino acids 312-595) of human NF2 isoform-1 was generated by the polymerase chain reaction using human fetal brain cDNA pool (CLONTECH) as template. The cDNA fragment was cloned into pMAL-c2X vector (New England BioLabs) to express the C-terminal NF2 protein segment as a fusion with the maltose-binding protein in Escherichia coli.

\section{Preparation of erythrocyte plasma membrane (ghosts)}

Freshly obtained erythrocytes from normal human subjects were washed four times with the wash buffer $(5.0 \mathrm{mM}$ sodium phosphate, $\mathrm{pH} 8.0,150 \mathrm{mM} \mathrm{NaCl}$, and $0.1 \mathrm{mM}$ EGTA). No samples were taken from NF2 patients in order to perform the experiments described here. The buffy coat was removed, and erythrocytes were filtered through the mixed cellulose column packed with 1:1 mixture of alpha-cellulose and Sigma Cell Type 50 to remove the residual leukocytes. The purity of gel-filtered erythrocytes was established by the Coulter counter (CELL DYN 4000) to confirm the removal of white blood cells in the final preparation. Purified erythrocytes were lysed by 20 volumes of the lysis buffer (5.0 mM sodium phosphate, $\mathrm{pH} 8.0,0.1 \mathrm{mM}$ EGTA, and $1.0 \mathrm{mM}$ PMSF), and the lysate was centrifuged for 20 minutes at $20,000 \mathrm{x} \mathrm{g}$ (Sorvall SS-34 rotor). The resultant membrane pellet (ghosts) was washed several times with the lysis buffer to remove hemoglobin, and ghosts were used the same day to avoid any detrimental effects of the freezing and thawing cycle on the membrane-protein interactions.

\section{Preparation of inside-out vesicles (IOVs)}

Erythrocyte ghosts were incubated in 30 volumes of $0.1 \mathrm{mM}$ EGTA, $\mathrm{pH} 8.5$, at $37^{\circ} \mathrm{C}$ for 30 minutes. This incubation step results in the extraction of spectrin, actin, and spectrin-actin-4.1 complexes from the plasma membrane. The membrane pellet containing sealed inside-out vesicles was washed with $5.0 \mathrm{mM}$ sodium phosphate $\mathrm{pH} 8.0,0.5 \mathrm{mM}$ EGTA, and vesicles were collected by centrifugation at $17,000 \mathrm{rpm}$ (Sorvall SS-34 rotor) for 30 minutes. IOVs were stripped of remaining peripheral membrane proteins by incubation with 30 volumes of $0.1 \mathrm{mM}$ EGTA, pH 11.0 , at $25^{\circ} \mathrm{C}$ for 20 minutes. The stripped vesicles were collected by centrifugation at 17,000 rpm (Sorvall SS-34 rotor) for 30 minutes, and washed twice with $5.0 \mathrm{mM}$ sodium phosphate, $\mathrm{pH} 8.0,0.5 \mathrm{mM}$ EGTA. The alkaline-stripped vesicles essentially contained the transmembrane proteins such 
as band 3 and glycophorins, but may have also retained some tightly associated peripheral membrane proteins.

\section{Extraction of NF2 protein from ghosts and IOVs}

Erythrocyte ghosts were incubated in the solubilization buffer (50 mM Tris-HCl, pH 7.5, 1.0 mM EGTA, 1.0 mM EDTA, and protease inhibitors) containing either $0.5 \%$ Triton $\mathrm{X}-100$ or no detergent in the presence of increasing concentration of $\mathrm{KCl}$. Incubations were carried out on ice for 60 minutes, and pellet was collected by centrifugation at 35,000 rpm (Beckman Type 42.2 Ti rotor) for 60 minutes. The supernatant was discarded and the membrane pellet was analyzed by $10 \%$ SDS/PAGE. Alternatively, the NF2 protein was extracted from IOVs by incubation with a solution of $1.0 \mathrm{M}$ potassium iodide containing $0.5 \mathrm{mM}$ EGTA, $\mathrm{pH} 8.0$, for 60 minutes at $23^{\circ} \mathrm{C}$.

\section{Purification of NF2 protein}

Ghosts were extracted in the solubilization buffer (as described above) containing $0.5 \%$ Triton X-100 on ice for 60 minutes. The detergent-extracted skeletal fraction (Triton shells) was dissociated by incubation with 10 volumes of low ionic strength buffer (3.0 mM Tris-HCl, pH 8.5, 0.5 mM EDTA, 2.0 mM DTT) for 45 minutes at $37^{\circ} \mathrm{C}$ followed by centrifugation at 40,000 rpm for 30 minutes (Beckman Type 42.2 Ti rotor). The supernatant, containing NF2 protein and other cytoskeletal proteins, was fractionated on a DEAE-Sephacel column $(2.5 \mathrm{x}$ $50 \mathrm{~cm})$ pre-equilibrated with the column buffer $(20 \mathrm{mM}$ Tris$\mathrm{HCl}, \mathrm{pH} 8.3$, $1.0 \mathrm{mM}$ EGTA, $1.0 \mathrm{mM}$ DTT, and $20 \mathrm{mM} \mathrm{KCl}$ ). Proteins that bound to the anion exchange column were eluted using a linear gradient of $20-500 \mathrm{mM} \mathrm{KCl}$ ( $800 \mathrm{ml}$ total volume) in the column buffer. Fractions enriched in NF2 protein, as assessed by Western blot analysis, were pooled, dialyzed against the column buffer, and further purified on a Mono Q column (FPLC). The Mono Q column was developed with a linear gradient of $20-400 \mathrm{mM} \mathrm{KCl}$ (50 ml total volume) in the column buffer and fractions containing purified NF2 protein were pooled, dialyzed, and concentrated using an Amicon membrane concentrator.

\section{Quantification of NF2 protein in human erythrocytes}

Two complementary approaches were used to determine the amount of NF2 protein in human erythrocytes. In the first approach, quantitative Western blotting was performed using ${ }^{125} \mathrm{I}-$ Protein A to detect antibodies bound to NF2 protein. Ghosts were isolated from a precise number of human erythrocytes, and analyzed by SDS-PAGE and Western blotting assays. Bands corresponding to NF2 protein were quantified using scintillation counting, as well as densitometric scanning of the Western blots. Purified NF2 protein, isolated from human erythrocyte ghosts, was used as a positive standard to calculate the amount of NF2 protein in ghosts. Increasing amount of purified NF2 protein was loaded, and the intensity of each band was compared with the NF2 protein signal from a pre-determined number of human erythrocytes. Alternatively, a recombinant C-terminal segment of NF2 protein was generated and purified, and used as a positive control to quantify the amount of NF2 protein in human erythrocytes. Experimentally, $6.0 \mathrm{ml}$ of freshly obtained human blood was collected in the ACD anticoagulant solution and erythrocytes free of leukocytes were obtained as described above. Ghosts were washed several times to remove hemoglobin, and used immediately for protein quantification. Protein concentration was determined either using Bradford protein assay (BioRad) or by densitometric scanning of the Coomassie-stained gels using BSA as control. Gel images were recorded using the BioRAD Gel Doc System and processed with the Quantity One Software.

\section{SDS-PAGE and Western blotting}

Proteins were resolved by $10 \%$ SDS-PAGE and blotted onto the nitrocellulose membrane. The nitrocellulose membrane was blocked with the blocking buffer $(6 \%$ casein, $1 \%$ polyvinyl pyrrolidone-40, $10 \mathrm{mM}$ EDTA in phosphate buffered saline, $\mathrm{pH}$ 7.4), and incubated with an anti-NF2 antibody at 1:1,000 dilution in the blocking buffer for two hours at room temperature. Blots were washed with the TBS-T buffer (10 mM Tris- $\mathrm{HCl}, \mathrm{pH} 7.5$, $150 \mathrm{mM} \mathrm{NaCl}$, and $0.1 \%$ Tween-20), and incubated for one hour with goat anti-rabbit IgG-horseradish peroxidase at 1: 1,500 in the blocking buffer. After repeated washings with TBS-T, the NF2 protein on the membrane was visualized using the ECL blot detection system (GE Healthcare).

\section{Immunocytochemistry}

Leukocyte-free erythrocytes were centrifuged at $800 \mathrm{rpm}$ onto Probe-On microscope glass slides (Baxter) using a Cytospin 3 (Shandon USA) for 5.0 minutes. Erythrocytes were washed once in the phosphate buffered saline (PBS), and then fixed with $4 \%$ formaldehyde for 5.0 minutes. This step was followed by three 5.0 minute washes in PBS. Immobilized erythrocytes were permeabilized with $0.1 \%$ Triton $\mathrm{X}-100$ in PBS for 5.0 minutes and washed again with PBS for 5 minutes. Slides were then rinsed twice in PBS for 5.0 minutes at room temperature, blocked for one hour at room temperature in PBS/1\% BSA $/ 1 \%$ normal goat serum, and washed in PBS for 5.0 minutes. The antiNF2 polyclonal antibody (1:100 dilution in PBS) was placed on the slides and incubated for one hour at room temperature. Slides were then washed in PBS prior to incubation with the goat antirabbit FITC (Sigma). Slides were mounted in antifade solution (BioRad) and viewed with a Zeiss inverted Microscope (Magnification X 1000). Photomicrographs were generated using a CCD camera (Cooke Corporation, USA), and digital images were processed using Phase 3 Imaging Software (Phase 3 Imaging USA).

\section{RESULTS}

\section{Expression of NF2 protein in mature erythrocytes}

We identified NF2 protein in mature erythrocytes, while using erythrocyte plasma membrane as a negative control during our previous studies of NF2 protein interactions with the PDZ domains of syntenin. ${ }^{16}$ To rule out the possibility of contamination from other white blood cells, we purified erythrocytes using a mixed cellulose resin to remove traces of leukocytes. The absence of white blood cells was confirmed by assessing the purity of erythrocytes by Coulter counter measurements, as described in the Experimental section. Human erythrocyte ghosts were prepared from freshly drawn blood and analyzed by Western blotting using an anti-NF2 polyclonal 


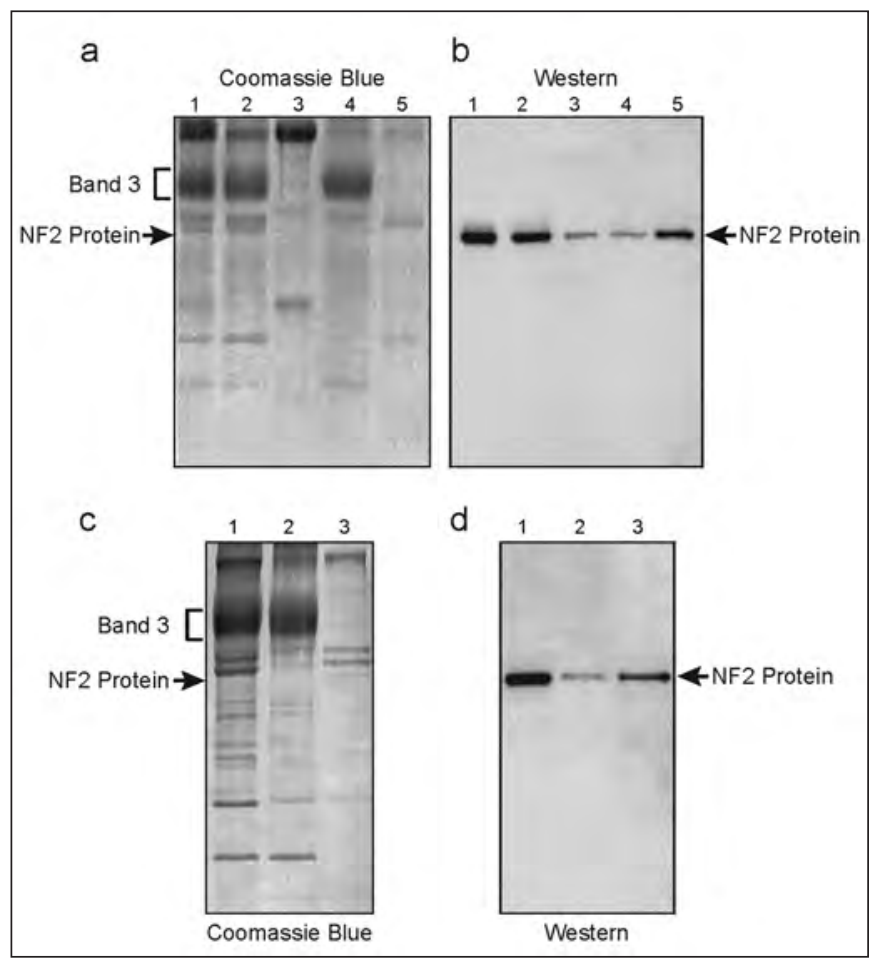

Figure 1: Detection of NF2 protein in human erythrocytes. (a) Coomassie blue staining of human erythrocyte membrane fractions. $10 \%$ SDS-PAGE. (b) Western blot analysis using anti-NF2 C-terminus polyclonal antibody. Lanes 1 (ghosts), 2 (IOVs), 3 (supernatant of IOVs enriched in spectrin and actin), 4 (IOVs stripped at $\mathrm{pH}$ 11), 5 (supernatant of $\mathrm{pH} 11$ extraction). The bulk of NF2 protein remains associated with IOVs (lane 2). A significant amount of NF2 protein is extracted after incubation of IOVs at pH 11 (lane 5). (c) Coomassie blue staining of IOVs extracted with $1.0 \mathrm{M}$ potassium iodide. (d) Western blot analysis. Lanes 1 (IOVs), 2 (IOVs extracted with 1.0 M KI), 3 (1.0 M KI supernatant). The bulk of NF2 protein was released from the IOVs after extraction with $1.0 \mathrm{M}$ potassium iodide.

antibody directed against the C-terminus of NF2 protein. ${ }^{23} \mathrm{~A}$ single polypeptide of $70 \mathrm{kDa}$ was detected in the human erythrocyte ghosts (Figure 1a \& b). Although a corresponding band at $\sim 70 \mathrm{kDa}$ is not discernible by Coomassie staining of the ghosts with moderate protein loading, as shown in Figure 1a (lane 1), a detectable band of $\sim 70 \mathrm{kDa}$ is visible in overloaded protein gels (data not shown). We confirmed the presence of NF2 protein by Western blotting using a second antibody directed against the N-terminus of NF2 protein. Moreover, the antipeptide polyclonal antibody directed against the $\mathrm{C}$-terminus of NF2 protein recognizes only the isoform- 1 of NF2 protein and not isoform-2. At this stage, it remains unknown whether the NF2 protein isoform-2 exists in erythrocytes. It is relevant to mention here that only NF2 protein isoform- 1 contains the binding sequence for the PDZ domains of syntenin, and has been shown to be a tumor suppressor in the transformation assays. ${ }^{16,26}$ To further confirm the presence of NF2 protein in mature erythrocytes, we examined intact erythrocytes by an immunofluorescence assay using a polyclonal antibody against the C-terminus of NF2 protein. Specific staining of NF2 protein was restricted to the plasma membrane compartment of permeabilized erythrocytes with no detectable signal in the cytosol (data not shown). Together, these results demonstrate that the mature erythrocytes contain NF2 protein isoform-1 as a single polypeptide of $70 \mathrm{kDa}$ associated with the plasma membrane.

\section{NF 2 protein is tightly associated with the erythrocyte plasma membrane}

Intact erythrocytes were lysed in the hypotonic solution to separate cytosol fraction from the plasma membrane by high speed centrifugation. Western blotting failed to detect any trace of NF2 protein in the cytosol fraction, whereas the anti-NF2 reactive polypeptide was exclusively associated with the plasma membrane. To further investigate the NF2 protein-membrane interactions, inside-out-vesicles (IOVs) were prepared from erythrocyte ghosts under low ionic strength solution conditions. This step removed the bulk of spectrin, actin, and spectrin-actinprotein 4.1-protein 4.9 complex from erythrocyte ghosts (Figure 1a, lanes 2,3). Western blotting indicated that the majority of NF2 protein remains associated with the IOVs (Figure 1b, lane 2). Since the IOVs still contain some peripheral membrane proteins, which could be dissociated by further extraction with an alkaline solution of $\mathrm{pH} 11$, we examined the elution of NF2 protein under these conditions (Figure 1a, lanes 4, 5). Western blotting indicates that $\sim 90 \%$ of NF2 protein is released from IOVs by extraction with a solution of $\mathrm{pH} 11$ (Figure 1b, lane 5). It is of interest to note that a relatively small pool ( 5-10\%) of NF2 protein still remained associated with the IOVs even after extraction with the $\mathrm{pH} 11$ solution (Figure $1 \mathrm{~b}$, lane 4). In addition, the IOVs were extracted with a solution of $1.0 \mathrm{M}$ potassium iodide, a treatment that is known to remove tightlybound peripheral membrane proteins (Figure 1c, lanes 2, 3). Indeed, extraction of IOVs with potassium iodide released $\sim 85 \%$ NF2 protein from the vesicles, but again could not remove a small pool of tightly associated NF2 protein (Figure 1d, lane 2). Together, these results indicate that the NF2 protein is tightly associated with the cytoplasmic face of the erythrocyte membrane.

\section{Association of NF2 protein with the erythrocyte membrane skeleton}

To investigate the nature of NF2 protein association with the erythrocyte membrane skeleton, ghosts were extracted with $0.5 \%$ Triton X-100, a non-ionic detergent, and the skeleton-associated NF2 protein was quantified by Western blotting. Sequential extraction of ghosts with Triton X-100 was carried out in the presence of increasing concentration of potassium chloride, as shown in Figure 2a. Interestingly, the NF2 protein remains associated with detergent-extracted skeletal fraction until the salt concentration is raised to $500 \mathrm{mM}$ (Figure 2b, lane 5). Solubilization of ghosts with $0.5 \%$ Triton X-100 and $500 \mathrm{mM}$ $\mathrm{KCl}$ or $\mathrm{NaCl}$ quantitatively released $\mathrm{NF} 2$ protein from the detergent-insoluble pellet, a feature akin to the known biochemical properties of lipid modified membrane proteins such as p55 and protein 4.2. ${ }^{27,28}$ Since the NF2 protein remains associated with the detergent-extracted skeletal fraction prepared in the presence of $150 \mathrm{mM}$ salt (Figure 2b, lane 4), we attempted to solubilize the NF2 protein by high salt in the absence of Triton 


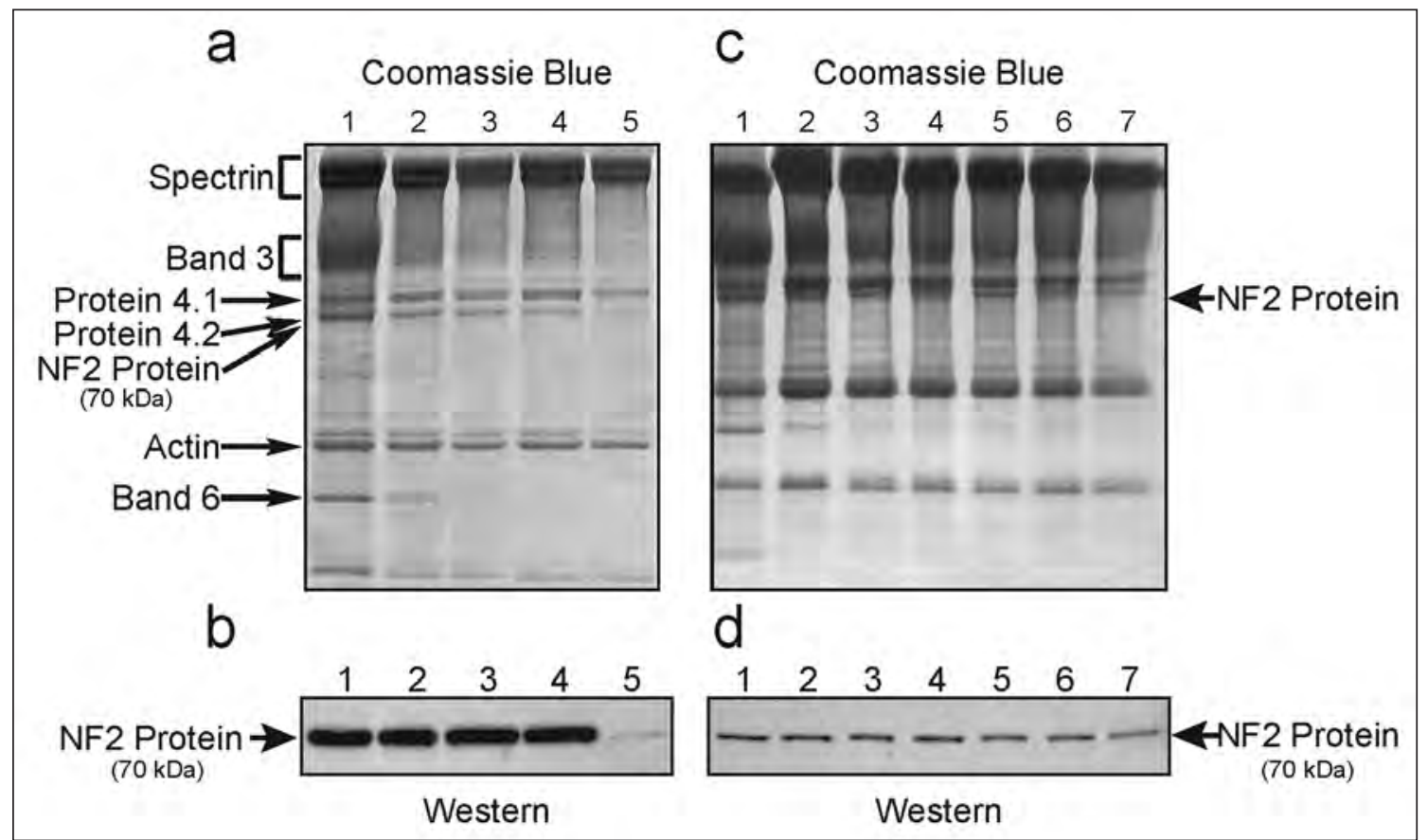

Figure 2: Triton X-100 mediated solubilization of human erythrocyte ghosts. (a) Coomassie blue staining of ghosts. 10\% SDS-PAGE. (b) Western blot analysis using anti-NF2 C-terminus polyclonal antibody. Solubilization buffer (SB) contains $50 \mathrm{mM}$ Tris-HCl, pH 7.5, $1.0 \mathrm{mM}$ EDTA, $1.0 \mathrm{mM}$ EGTA, and protease inhibitors. Lanes 1 (ghosts), 2 (ghosts extracted with 0.5\% Triton X-100 in SB), 3 (same as lane 2 plus $50 \mathrm{mM} \mathrm{KCl),} 4$ (same as lane 2 plus $150 \mathrm{mM} \mathrm{KCl}$ ), 5 (same as lane 2 plus $500 \mathrm{mM} \mathrm{KCl).} \mathrm{Note} \mathrm{that} \mathrm{the} \mathrm{NF2} \mathrm{protein} \mathrm{remains} \mathrm{associated} \mathrm{with} \mathrm{the} \mathrm{cytoskeletal} \mathrm{fraction} \mathrm{after} \mathrm{extraction} \mathrm{of} \mathrm{ghosts}$ with Triton X-100 in the presence of $150 \mathrm{mM}$ salt. However, extraction of ghosts with $0.5 \%$ Triton X-100 containing $500 \mathrm{mM} \mathrm{KCl}$ completely solubilized the NF2 protein. (c) Coomassie blue staining of ghosts and cytoskeletal fraction. Ghosts were extracted with $0.5 \%$ Triton X-100 containing $150 \mathrm{mM} \mathrm{KCl.}$ Cytoskeletal pellet was recovered by centrifugation on a cushion of sucrose. Detergent-free cytoskeleton was then extracted with an increasing concentration of salt. Lanes 1 (ghosts), 2 (cytoskeleton pellet), 3 (pellet extracted with $200 \mathrm{mM}$ salt), 4 (same as lane 2 plus $400 \mathrm{mM}$ salt), 5 (same as lane 2 plus $600 \mathrm{mM}$ salt), 6 (same as lane 2 plus $800 \mathrm{mM}$ salt, 7 (same as lane 2 plus $1.0 \mathrm{M}$ salt). (d) Western blot analysis using anti-NF2 C-terminus polyclonal antibody. Note that the NF2 protein is not released from the cytoskeletal fraction even at $1.0 \mathrm{M}$ salt in the absence of Triton X-100.

$\mathrm{X}-100$. Ghosts were extracted with $0.5 \%$ Triton $\mathrm{X}-100$ containing $150 \mathrm{mM}$ salt and the skeletal pellet was recovered by centrifugation on a cushion of sucrose. Detergent-free (or reduced) skeletal pellet was then extracted with high concentration of salt. The NF2 protein remained tightly associated with the skeletal fraction, even in the presence of 1.0 M salt (Figure 2c, d). A parallel Western blot analysis indicated that the bulk of ankyrin is released from the skeletal fraction under these conditions (data not shown). Together, these results suggest that the mode of NF2 protein association with the erythrocyte cytoskeleton is unlike proteins such as spectrin, actin, protein 4.1, dematin, and ankyrin, but appears to be similar to the properties of lipid modified p55 and protein 4.2.

\section{Purification of native NF2 protein from human erythrocytes}

Guided by the biochemical properties of erythrocyte NF2 protein, as outlined above, we devised a purification strategy to isolate native NF2 protein from human erythrocytes. Since the bulk of NF2 protein remains associated with the Triton X-100 insoluble cytoskeletal fraction, ghosts were extracted with $0.5 \%$ Triton X-100 at low ionic strength and the detergent-insoluble pellet was washed to remove excess detergent. The washed cytoskeletal pellet was dissociated at low ionic strength at $37^{\circ} \mathrm{C}$ in the absence of any detergent. The dissociated soluble proteins were then fractionated by anion exchange chromatography using DEAE-Sephacel and Mono Q columns, respectively. The elution of the $70 \mathrm{kDa} N F 2$ polypeptide was monitored by Western blotting. From the DEAE-Sephacel column, the $70 \mathrm{kDa}$ NF2 protein begins to elute at a salt concentration that co-elutes p55 and dematin, and the NF2 protein elution continues in fractions containing protein 4.1 (Figure 3a, fractions 25-29, see arrow). Fractions enriched with NF2 protein were pooled, dialyzed, and further purified on a Mono Q column, as described in the Experimental section (Figure 3c, d). Purified NF2 protein was stored in $25 \%$ glycerol under frozen conditions. In a typical protein purification protocol, $\sim 500-600$ microgram of purified NF2 protein was obtained from one unit of packed erythrocytes. The purified NF2 protein migrated as a single band on Coomassie stained polyacrylamide gels, with an estimated purity of $\sim 95 \%$ or greater (Figure 3c).

It is noteworthy that although we have presented only one purification scheme here (Figure 4, scheme \#1), in principle the NF2 protein could be isolated from ghosts using at least two other purification schemes. In the second approach (Figure 4, scheme \#2), ghosts were extracted with Triton X-100 containing $150 \mathrm{mM}$ salt to remove additional cytoskeleton-associated 


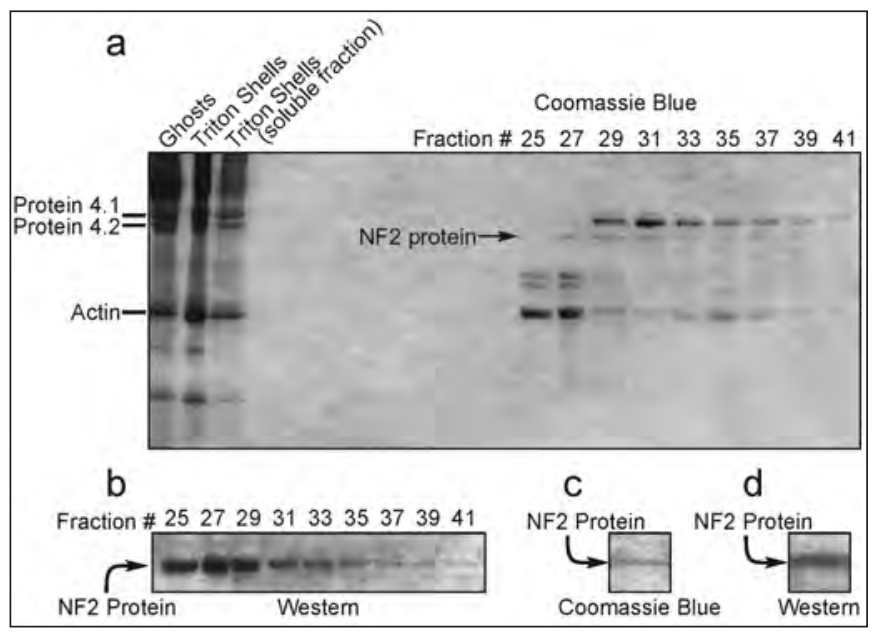

Figure 3: Purification of NF2 protein from the Triton shells. Triton shells were prepared as described in the Experimental section and dissociated by incubation in 10 volumes of low ionic strength buffer (3.0 $\mathrm{mM}$ Tris- $\mathrm{HCl}, \mathrm{pH}$ 8.5, $0.5 \mathrm{mM}$ EDTA, $2.0 \mathrm{mM} \mathrm{DTT)}$ at $37^{\circ} \mathrm{C}$. The supernatant was loaded on the DEAE-Sephacel column. (a) DEAESephacel eluted fractions were analyzed by SDS-PAGE, followed by Coomassie blue staining, and (b) Western blot analysis using anti-NF2 $C$-terminus polyclonal antibody. The DEAE-Sephacel-eluted fractions enriched in NF2 protein were pooled, dialyzed, and loaded on a Mono $Q$ column. Fractions containing purified NF2 protein were pooled, dialyzed, and concentrated. (c) Coomassie blue staining of purified NF2 protein. (d) Western blot analysis of purified NF2 protein.

proteins. The NF2 protein was released from the detergentinsoluble fraction by further solubilization in a solution of Triton X-100 containing $500 \mathrm{mM}$ salt. Although we did not pursue purification of this material further, the NF2 protein could be isolated from the detergent-soluble fraction using immunoaffinity and hydrophobic chromatography steps. Finally, a third purification scheme was designed to isolate detergent-free NF2 protein from erythrocyte ghosts. Biochemical extraction with 1.0 $\mathrm{M}$ potassium iodide released the bulk of NF2 protein from the inside-out-vesicles (Figure 4, scheme \#3). Subsequent purification of salt-extracted NF2 protein could be achieved by ion exchange chromatography steps as described above. Together, these purification strategies outline a feasible experimental approach to isolate native NF2 protein of mammalian origin, suitable for various biochemical assays in the future.

\section{Determination of NF2 protein copy number in human erythrocytes}

An immunoblot assay was developed to determine the number of NF2 protein molecules in human erythrocytes. Ghosts were prepared from a precisely determined number of human erythrocytes and purified NF2 protein was used as a positive standard. The NF2 protein signal was detected using antibodies specific for both N- and C- termini of NF2 protein. Quantification of bound antibodies by ${ }^{125}$ I-Protein A estimated $\sim 40,300$ molecules of NF2 protein per erythrocyte (Figure 5). Alternatively, a recombinant $\mathrm{C}$-terminal segment of NF2 protein was expressed, and used as a positive control, to quantify NF2 protein in human ghosts. Quantitative immunoblot analysis estimated $\sim 65,000$ copies of NF2 protein per erythrocyte. To further confirm the accuracy of the immunoblot assay, we determined the number of p55 molecules in erythrocytes by using a recombinant GST fusion protein linked to the SH3Guanylate kinase segment of p55. ${ }^{29} \mathrm{~A}$ quantitative immunoblot analysis estimated $\sim 70,000$ copies of p55 per erythrocyte. This value compares reasonably well with the previously reported $\sim 80,000$ copies of p55 per erythrocyte, which was originally estimated by using native $\mathrm{p} 55$ as a positive control. ${ }^{30}$

\section{NF2 protein expression in mutant erythrocytes}

Erythrocytes with defined mutations in the membrane proteins have often served as a paradigm to discover novel

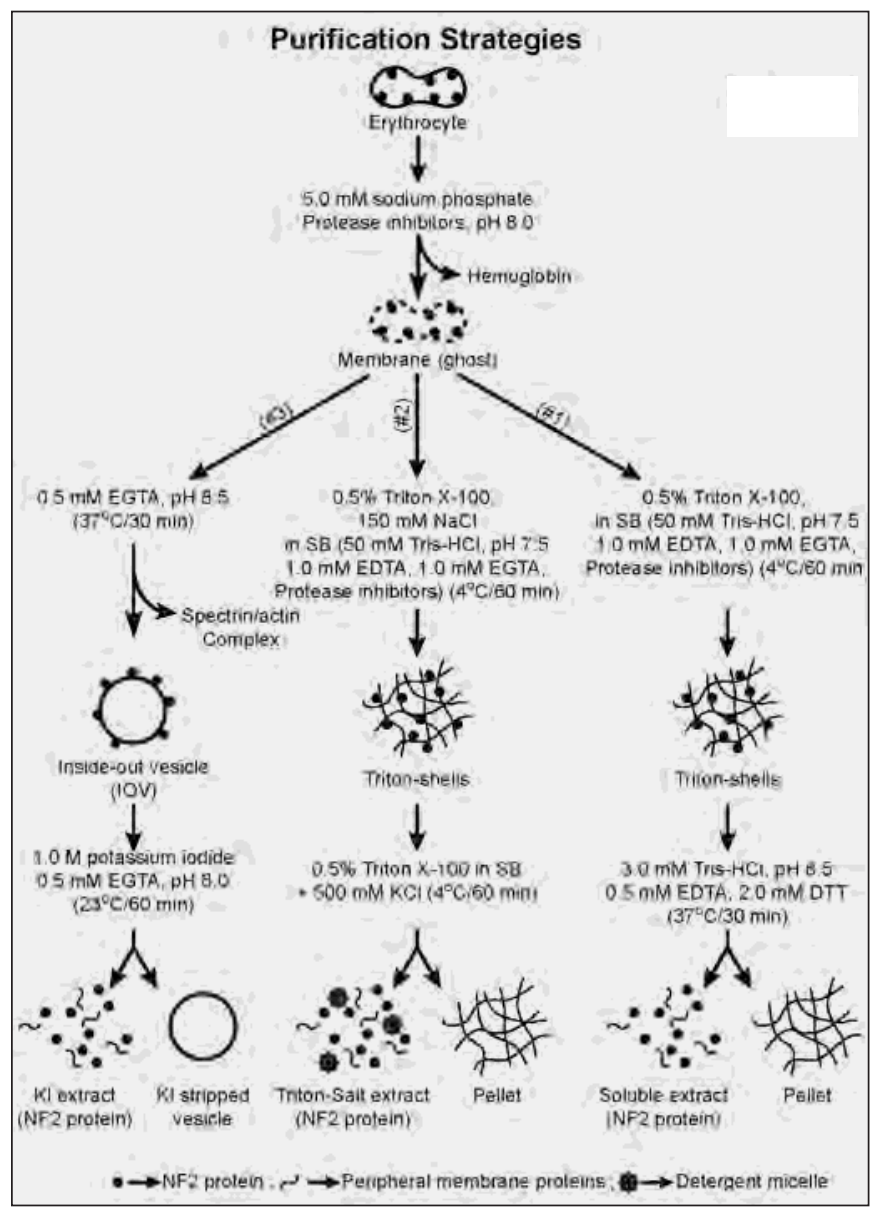

Figure 4: Schematic flow diagram of various purification schemes for erythrocyte NF2 protein. The steps for the NF2 protein purification shown in Figure 3 are outlined in scheme \#1. Scheme \#2 outlines a procedure to isolate NF2 protein by releasing the protein in Triton X-100 in the presence of $500 \mathrm{mM}$ salt. This approach may increase the yield of purified NF2 protein substantially. Finally, in scheme \#3, an experimental approach is presented where NF2 protein could be isolated without the use of any non-ionic detergents. The yield of purified protein is generally low using this purification scheme. 


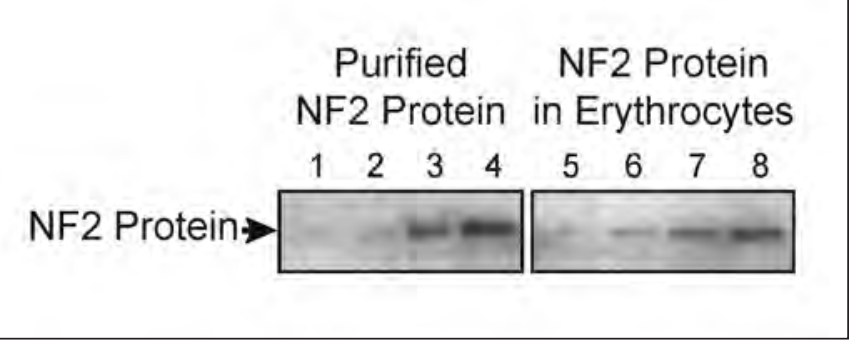

Figure 5: Determination of the number of copies of NF2 protein in human erythrocytes. Quantitative Western blot analysis was performed using an increasing amount of NF2 protein purified from human erythrocytes. Amount of NF2 protein in lanes 1 (24 ng), 2 (48 ng), 3 (96 $\mathrm{ng})$, and $4(192 \mathrm{ng})$. Human erythrocyte ghosts isolated from a fixed number of erythrocytes were loaded in each lane. Lanes $5\left(5 \times 10^{6}\right), 6(10$ $\left.\times 10^{6}\right), 7\left(20 \times 10^{6}\right)$, and $8\left(40 \times 10^{6}\right) .{ }^{125 I}$-Protein $A$ was used to detect the amount of NF2 protein-bound antibodies, and bands corresponding to NF2 protein were quantified by densitometric scanning. A similar analysis was performed using a recombinant domain of NF2 protein (data not shown).

protein-protein interactions. ${ }^{24,31}$ For example, the loss of p55 in protein 4.1 null human erythrocytes led to the identification of the ternary complex between p55, protein 4.1, and glycophorin C. ${ }^{24}$ Similarly, the loss of glycophorin A in band 3 null mouse erythrocytes provided further genetic evidence for the existence of band 3-glycophorin A complex in the erythrocyte plasma membrane. ${ }^{32}$ Using a Western blot assay, we examined the expression of NF2 protein in human and mouse erythrocytes lacking protein 4.1, glycophorin $\mathrm{C}, \mathrm{p} 55, \mathrm{nb} / \mathrm{nb}$ ankyrin mutant protein, alpha spectrin, band 3 , and band 4.2. No significant deficiency of NF2 protein was observed in these mutant erythrocytes (Figure 6). It is noteworthy here that the presence of NF2 protein in mutant erythrocyte ghosts does not rule out the possibility of weakened membrane interactions of NF2 protein as a consequence of defined mutations.

\section{DiscuSSION}

The cloning of NF2 tumor suppressor gene in 1993 revealed a novel pathway for the regulation of cell proliferation and differentiation cascade presumably by factors acting at the interface of the membrane-cytoskeleton. ${ }^{33,34}$ Since then, this paradigm has remained a guiding principle for functional characterization of NF2 protein, also known as Merlin or Schwannomin, in numerous cellular processes. The primary structure of NF2 protein includes an amino-terminal FERM domain and a carboxyl terminal tail domain, thus categorizing the tumor suppressor into the Protein 4.1 superfamily. To date, considerable efforts have been made to identify proteins that interact with NF2 protein and elucidate its function in vitro and in vivo. Despite the intense interest in the signaling pathways of NF2 protein, little is known about the biochemical properties of native NF2 protein. This gap exists mainly because the endogenous NF2 protein has never been purified from mammalian cells. Although the phosphorylation status of NF2 protein has been examined in some detail, it is not known

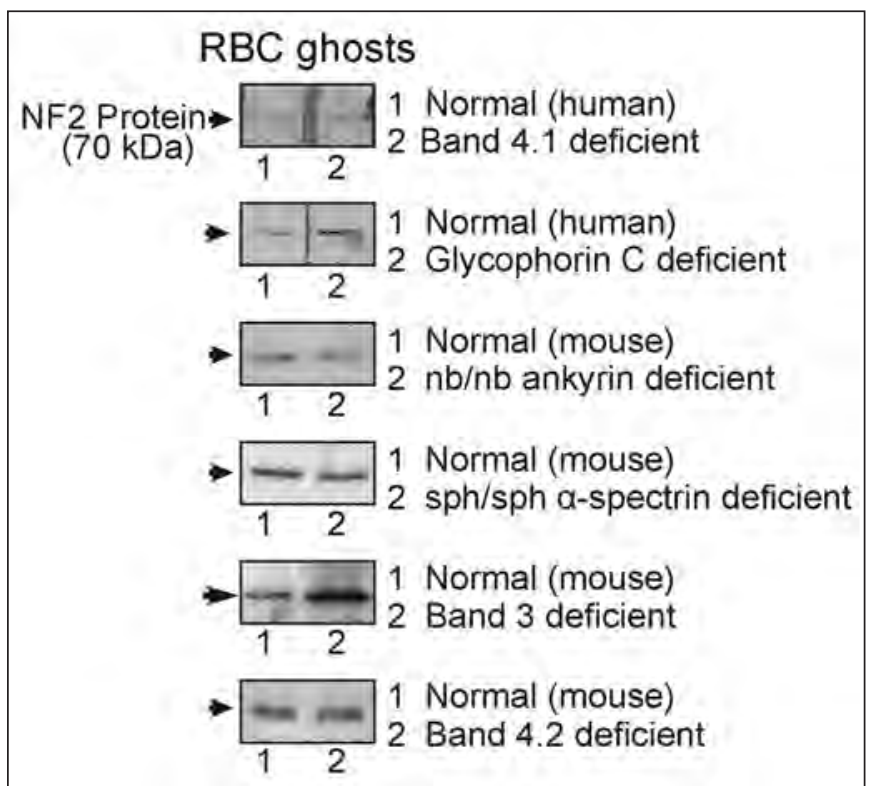

Figure 6: Western blot analysis of NF2 protein in the mutant erythrocytes. Ghosts were isolated from human/mouse erythrocytes deficient in various proteins. After SDS-PAGE and electro-blotting, the presence of NF2 protein was examined by Western blot analysis. The presence of NF2 protein in the mutant erythrocyte plasma membrane suggests that the binding of NF2 protein to various cytoskeletal proteins is not essential for its retention on the erythrocyte plasma membrane. At this stage, we could not perform a detailed study of the membrane protein interactions of NF2 protein because of the limited quantity of mutant mouse erythrocyte ghosts obtained from various sources.

whether its tumor suppressor activity requires regulation by other post-translational modifications such as lipids and proteinprotein interactions. With this perception, the identification of NF2 protein as a constituent of the erythrocyte plasma membrane provided a unique opportunity to isolate native NF2 protein of human origin from a well characterized plasma membrane.

This report presents the first identification and purification of NF2 protein from the human erythrocyte plasma membrane. The anti-peptide polyclonal antibody raised against the carboxylterminus of NF2 protein recognizes only the isoform-1 of NF2 protein. The NF2 protein isoform-1, which contains a PDZbinding sequence at the carboxyl-terminus, has been shown to function as a tumor suppressor. ${ }^{16}$ In contrast, the NF2 protein isoform-2 lacking a PDZ-binding motif is not active as a tumor suppressor. At this stage it is not known whether the NF2 isoform-2 exists in the erythrocytes. It is of interest to note that the amino-terminus specific polyclonal antibody (A-19) against NF2 protein detected only a single polypeptide in the human erythrocyte ghosts suggesting that the isoform-1 is presumably the dominant polypeptide in the erythrocyte membrane. A single polypeptide of $70 \mathrm{kDa}$ encoding the NF2 protein is associated exclusively with the erythrocyte plasma membrane, and no trace of soluble NF2 protein was observed in the cytosol. The membrane-bound NF2 polypeptide appears to be quite stable, 
since no evidence of proteolysis under a variety of membrane extraction and solubilization conditions was found. The NF2 protein remains tightly associated with the plasma membrane, even after the removal of $\sim 90 \%$ spectrin and actin from the membrane vesicles (Figure 1). Intriguingly, the NF2 protein remained bound to the detergent-insoluble skeletal fraction (Triton shells) upon extraction with Triton X-100 in the presence of low to moderate ionic strength (Figure 2). In contrast, the NF2 protein was rapidly released from the Triton shells when ghosts were extracted with Triton X-100 in the presence of $0.5 \mathrm{M}$ salt (Figure 2). This biochemical property of NF2 protein is more akin to the known characteristics of erythrocyte p55 and protein 4.2 , both of which are lipid conjugated peripheral membrane proteins. ${ }^{28,30}$ At this stage, it is not known whether the NF2 protein contains any bound lipid that is required for its interaction with the erythrocyte plasma membrane.

The NF2 protein purification scheme, as outlined in Figures $3-4$, was devised largely based on previous experience with the purification of erythrocyte p55 and dematin. ${ }^{35,36}$ This experimental strategy was selected because of the observed biochemical similarities between NF2 protein and erythrocyte p55 and protein 4.2. In principle, several alternate purification schemes could be developed in the future, including the isolation of detergent-free NF2 protein, resulting in even higher protein yields (Figure 4). At this stage, we did not explore further purification of NF2 protein from the detergent extract of erythrocyte ghosts at high ionic strength because of the inefficiency of ion-exchange chromatography to achieve NF2 protein purification in the presence of Triton X-100. Quantification of NF2 protein using two independent internal standards revealed $\sim 41,000$ and $\sim 65,000$ copies of NF2 protein, respectively, in the human erythrocyte plasma membrane. Interestingly, the NF2 protein copy number of $\sim 65,000$ determined by the recombinant protein method compares well with the $\sim 70,000$ copies of p55, also calculated using the recombinant protein method, present in the erythrocyte membrane. In contrast, our previous estimate of $\sim 80,000$ copies of p55 per erythrocyte was determined using native and purified erythrocyte p55 as an internal standard. ${ }^{30}$ In summary, the abundance of NF2 protein in human erythrocytes is stoichiometrically comparable to other significant proteins of the plasma membrane.

One rationale to further pursue biochemical characterization of NF2 protein in the erythrocytes comes from the protocol of using the erythrocyte plasma membrane from models of hemolytic anemia to uncover novel binding partners. Since the polyclonal antibody against the carboxyl-terminus of NF2 protein can detect both human and mouse forms, we tested a set of mutant erythrocytes from human and mouse models of hemolytic anemia for the loss of NF2 protein (Figure 6). Although we did not detect any significant loss of NF2 protein in the mutant erythrocytes examined to date, this does not rule out the possibility of independent interactions of NF2 protein with at least some of these proteins such as spectrin, protein 4.2, and p55. Clearly, the identification of NF2 protein in the erythrocyte membrane will now make it feasible to utilize a variety of biochemical approaches to identify novel binding partners in the future.

It is interesting to speculate that the identification of a stable $70 \mathrm{kDa}$ polypeptide encoding the NF2 protein in the erythrocyte membrane may open up new avenues for the development of a simple Western blot-based assay to detect NF2 gene mutations in patients. A modified diagnostic assay could also be developed that can detect truncated NF2 polypeptides in the presence of a normal allele; this is currently not always possible by PCR techniques because truncations can occur at various position of the protein. Combining such information with genetic testing could lead to invaluable insights into the progression of NF2 disease in clinical settings.

\section{ACKNOWLEDGEMENTS}

We are grateful to Kaori Horiguchi and Donna MarieMironchuk for technical help with the drawing of figures and Kelly O'Brien for valuable editorial assistance. This work was supported by the Department of Defense Neurofibromatosis Research Program and a Career Development Award NF020087 from the Department of Defense and HL 60755 from the National Institutes of Health.

\section{REFERENCES}

1. Lutchman M, Rouleau GA. Neurofibromatosis type 2: a new mechanism of tumor suppression. Trends Neurosci. 1996; 19(9): 373-7.

2. Parry DM, MacCollin MM, Kaiser-Kupfer MI, Pulaski K, Nicholson HS, Bolesta M, et al. Germ-line mutations in the neurofibromatosis 2 gene: correlations with disease severity and retinal abnormalities. Am J Hum Genet. 1996; 59(3):529-39.

3. Bretscher A, Edwards K, Fehon RG. ERM proteins and merlin: integrators at the cell cortex. Nat Rev Mol Cell Biol. 2002; 3(8): 586-99.

4. Gautreau A, Louvard D, Arpin M. ERM proteins and NF2 tumor suppressor: the Yin and Yang of cortical actin organization and cell growth signaling. Curr Opin Cell Biol. 2002; 14(1): 104-9.

5. Conboy J, Kan YW, Shohet SB, Mohandas N. Molecular cloning of protein 4.1, a major structural element of the human erythrocyte membrane skeleton. Proc Natl Acad Sci USA. 1986; 83(24):9512-6.

6. Lim DJ, Rubenstein AE, Evans DG, Jacks T, Seizinger BG, Baser $\mathrm{ME}$, et al. Advances in neurofibromatosis 2 (NF2): a workshop report. J Neurogenet. 2000; 14(2):63-106.

7. McClatchey AI, Saotome I, Mercer K, Crowley D, Gusella JF, Bronson RT, et al. Mice heterozygous for a mutation at the Nf2 tumor suppressor locus develop a range of highly metastatic tumors. Genes Dev. 1998; 12(8):1121-33.

8. Kissil JL, Wilker EW, Johnson KC, Eckman MS, Yaffe MB, Jacks T. Merlin, the product of the Nf2 tumor suppressor gene, is an inhibitor of the p21-activated kinase, Pak1. Mol Cell. 2003; 12(4):841-9.

9. Shaw RJ, Paez JG, Curto M, Yaktine A, Pruitt WM, Saotome I, et al. The Nf2 tumor suppressor, Merlin, functions in rac-dependent signaling. Develop Cell. 2001; 1:63-72.

10. Shaw RJ, McClatchey AI, Jacks T. Regulation of the neurofibromatosis type 2 tumor suppressor protein, Merlin, by adhesion and growth arrest stimuli. J Biol Chem. 1998; 273(13): 7757-64.

11. Rong R, Tang X, Gutmann DH, Ye K. Neurofibromatosis 2 (NF2) tumor suppressor merlin inhibits phosphatidylinositol 3-kinase through binding to PIKE-L. Proc Natl Acad Sci U.S.A. 2004; 101(52):18200-5.

12. Manchanda N, Lyubimova A, Ho HY, James MF, Gusella JF, Ramesh N, et al. The NF2 tumor suppressor Merlin and the ERM proteins interact with N-WASP and regulate its actin polymerization function. J Biol Chem. 2005; 280(13):12517-22.

13. Chene P. The role of tetramerization in p53 function. Oncogene. 2001; 20(21):2611-7. 
14. Resh MD. Membrane targeting of lipid modified signal transduction proteins. Subcell Biochem. 2004; 37:217-32.

15. Johnson KC, Kissil JL, Fry JL, Jacks T. Cellular transformation by a FERM domain mutant of the Nf2 tumor suppressor gene. Oncogene. 2002; 21(39):5990-7.

16. Jannatipour M, Dion P, Khan S, Jindal H, Fan X, Laganiere J, et al. Schwannomin isoform-1 interacts with syntenin via PDZ domains. J Biol Chem. 2001; 276(35):33093-100.

17. Pearson MA, Reczek D, Bretscher A, Karplus PA. Structure of the ERM protein moesin reveals the FERM domain fold masked by an extended actin binding tail domain. Cell. 2000; 101(3): 259-70.

18. Nguyen R, Reczek D, Bretscher A. Hierarchy of merlin and ezrin Nand C-terminal domain interactions in homo- and heterotypic associations and their relationship to binding of scaffolding proteins EBP50 and E3KARP. J Biol Chem. 2001; 276(10): 7621-9.

19. Xiao GH, Gallagher R, Shetler J, Skele K, Altomare DA, Pestell RG, et al. The NF2 tumor suppressor gene product, merlin, inhibits cell proliferation and cell cycle progression by repressing cyclin D1 expression. Mol Cell Biol. 2005; 25(6):2384-94.

20. Rangwala R, Banine F, Borg JP, Sherman LS. Erbin regulates mitogen-activated protein (MAP) kinase activation and MAP kinase-dependent interactions between Merlin and adherens junction protein complexes in Schwann cells. J Biol Chem. 2005; 280(12):11790-7.

21. Rong R, Surace EI, Haipek CA, Gutmann DH, Ye K. Serine 518 phosphorylation modulates merlin intramolecular association and binding to critical effectors important for NF2 growth suppression. Oncogene. 2004; 23(52):8447-54.

22. Kimura Y, Koga H, Araki N, Mugita N, Fujita N, Takeshima H, et al. The involvement of calpain-dependent proteolysis of the tumor suppressor NF2 (merlin) in schwannomas and meningiomas. Nat Med. 1998; 4(8):915-22.

23. Claudio JO, Lutchman M, Rouleau GA. Widespread but cell-type specific expression of the mouse neurofibromatosis type 2 gene. Neuroreport. 1995, 6(14):1942-6.

24. Alloisio N, Dalla Venezia N, Rana A, Andrabi K, Texier P, Gilsanz $\mathrm{F}$, et al. Evidence that red blood cell protein p55 may participate in the skeleton-membrane linkage that involves protein 4.1 and glycophorin C. Blood. 1993; 82(4):1323-7.

25. Southgate CD, Chishti AH, Mitchell B, Yi SJ, Palek J. Targeted disruption of the murine erythroid band 3 gene results in spherocytosis and severe haemolytic anaemia despite a normal membrane skeleton. Nat Genet. 1996; 14(2):227-30.

26. Lutchman M, Rouleau GA. The neurofibromatosis type 2 gene product, schwannomin, suppresses growth of NIH 3T3 cells. Cancer Res. 1995; 55(11):2270-4.
27. Chishti AH. Function of p55 and its nonerythroid homologues. Curr Opin Hema. 1998; 5(2):116-21.

28. Risinger MA, Dotimas EM, Cohen CM. Human erythrocyte protein 4.2 , a high copy number membrane protein, is N-myristylated. J Biol Chem. 1992; 267(8):5680-5.

29. Marfatia SM, Lue RA, Branton D, Chishti AH. Identification of the protein 4.1 binding interface on glycophorin $\mathrm{C}$ and $\mathrm{p} 55$, a homologue of the Drosophila discs-large tumor suppressor protein. J Biol Chem. 1995; 270(2):715-9.

30. Ruff P, Speicher DW, Husain-Chishti A. Molecular identification of a major palmitoylated erythrocyte membrane protein containing the src homology 3 motif. Proc Natl Acad Sci USA. 1991; 88(15):6595-9.

31. Lux SE, Palek J. Disorders of the red cell membrane. In: Handin RI, Lux SE, Stossel TP, editors. Blood: principles and practice of hematology. Philadelphia: Lippincott Company; 1995. p. 1701-18.

32. Hassoun H, Hanada T, Lutchman M, Sahr KE, Palek J, Hanspal M, et al. Complete deficiency of glycophorin A in red blood cells from mice with targeted inactivation of the band 3 (AE1) gene. Blood. 1998; 91(6):2146-51.

33. Trofatter JA, MacCollin MM, Rutter JL, Murrell JR, Duyao MP, Parry DM, et al. A novel moesin-, ezrin-, radixin-like gene is a candidate for the neurofibromatosis 2 tumor suppressor. Cell. 1993; 75(4):826.

34. Rouleau GA, Merel P, Lutchman M, Sanson M, Zucman J, Marineau $\mathrm{C}$, et al. Alteration in a new gene encoding a putative membrane-organizing protein causes neuro-fibromatosis type 2 . Nature. 1993; 363(6429):515-21.

35. Chishti A, Levin A, Branton D. Abolition of actin-bundling by phosphorylation of human erythrocyte protein 4.9. Nature. 1988; 334(6184):718-21.

36. Chishti A, Faquin W, Wu CC, Branton D. Purification of erythrocyte dematin (protein 4.9) reveals an endogenous protein kinase that modulates actin-bundling activity. J Biol Chem. 1989; 264(15):8985-91. 